\title{
Adverse Respiratory Health and Hematological Alterations among Agricultural Workers Occupationally Exposed to Organophosphate Pesticides: A Cross- Sectional Study in North India
}

\author{
Mohd. Fareed, Manoj Kumar Pathak, Vipin Bihari, Ritul Kamal, Anup Kumar Srivastava, \\ Chandrasekharan Nair Kesavachandran*
}

Epidemiology Division, CSIR - Indian Institute of Toxicology Research (CSIR-IITR), Lucknow, India

\begin{abstract}
Background: Non-protective work practices followed by farm workers during spraying of pesticides lead to occupational exposure among them.

Objective: This study is designed to explore the respiratory health and hematological profile of agricultural workers occupationally exposed to OP pesticides.

Materials and Methods: A cross sectional study was undertaken among 166 pesticide sprayers working in mango orchards of Lucknow district in North India compared with 77 controls to assess the respiratory illness, lung functions, cholinesterase levels and hematological profile. A questionnaire based survey and clinical examination for respiratory health were conducted among study subjects. Lung function test was conducted among study subjects by using spirometer. Cholinesterase level as biomarker of OP pesticides and hematological profile of study subjects were investigated in the laboratory by following the standard protocols.

Results: Overall respiratory morbidity observed among exposed subjects was $36.75 \%$. Symptoms for respiratory illness like dry cough, productive cough, wheezing, irritation of throat and blood stained sputum were found to be significantly more $(p<0.05)$ among pesticide sprayers than controls. Lung function parameters viz. PEFR, FEV,$\%$ PEFR predicted, \%FEV predicted and $\mathrm{FEV}_{1} / \mathrm{FVC}$ were found to be significantly decreased $(p<0.05)$ among pesticide sprayers as compared to controls. Exposure wise distribution of respiratory illness and lung functions among pesticide sprayers show that the exposure duration significantly elevates $(p<0.05)$ the respiratory problems and significantly decreases $(p<0.001)$ lung functions among pesticide sprayers. Activities of acetylcholinesterase and butyrylcholinesterase were found to be significantly depleted $(p<0.001)$ among pesticide sprayers as compared to controls which show the exposure of OP pesticides among them. The hematological profile viz. RBC, WBC, monocytes, neutrophils, MCV, MCH, MCHC and platelet count were significantly altered $(p<0.001)$ in pesticide sprayers than controls.
\end{abstract}

Conclusion: This study shows that the unsafe occupational exposure of OP pesticides causes respiratory illness, decreased lung functions and hematological alterations among pesticide sprayers.

Citation: Fareed M, Pathak MK, Bihari V, Kamal R, Srivastava AK, et al. (2013) Adverse Respiratory Health and Hematological Alterations among Agricultura Workers Occupationally Exposed to Organophosphate Pesticides: A Cross-Sectional Study in North India. PLoS ONE 8(7): e69755. doi:10.1371/journal.pone.0069755

Editor: Thomas H. Thatcher, University of Rochester Medical Center, United States of America

Received February 26, 2013; Accepted June 11, 2013; Published July 25, 2013

Copyright: (C) 2013 Fareed et al. This is an open-access article distributed under the terms of the Creative Commons Attribution License, which permits unrestricted use, distribution, and reproduction in any medium, provided the original author and source are credited.

Funding: This study is a part of a project (CST/SERPD/D-860) financially supported by Uttar Pradesh Council of Science \& Technology (UP-CST) Lucknow, India. The publication charges have been funded by institutional project BSC- 011. Additionally, one of the authors (MF) received Senior Research Fellowship and contingency grant for this study from Council of Scientific and Industrial Research (CSIR), New Delhi, India. The funders had no role in study design, data collection and analysis, decision to publish, or preparation of the manuscript.

Competing Interests: The authors have declared that no competing interests exist.

* E-mail: ckchandran@iitr.res.in

\section{Introduction}

In developing countries including India, agricultural workers who are engaged in the occupation of spraying pesticides in crops get the direct exposure of pesticides due to unsafe and nonpreventive work practices. They do not use the Personal Protective Equipments (PPE) like safety masks, gloves etc. during the aerial spraying of pesticides resulting in the entry of pesticides in the blood stream via respiratory tract through inhalation which can adversely affect respiratory system and can also cause hematological alterations among agricultural workers.

Several earlier studies [1-4] have reported increased risk of respiratory problems, such as asthma, wheeze and chronic bronchitis among agricultural workers. Pesticides after reaching 

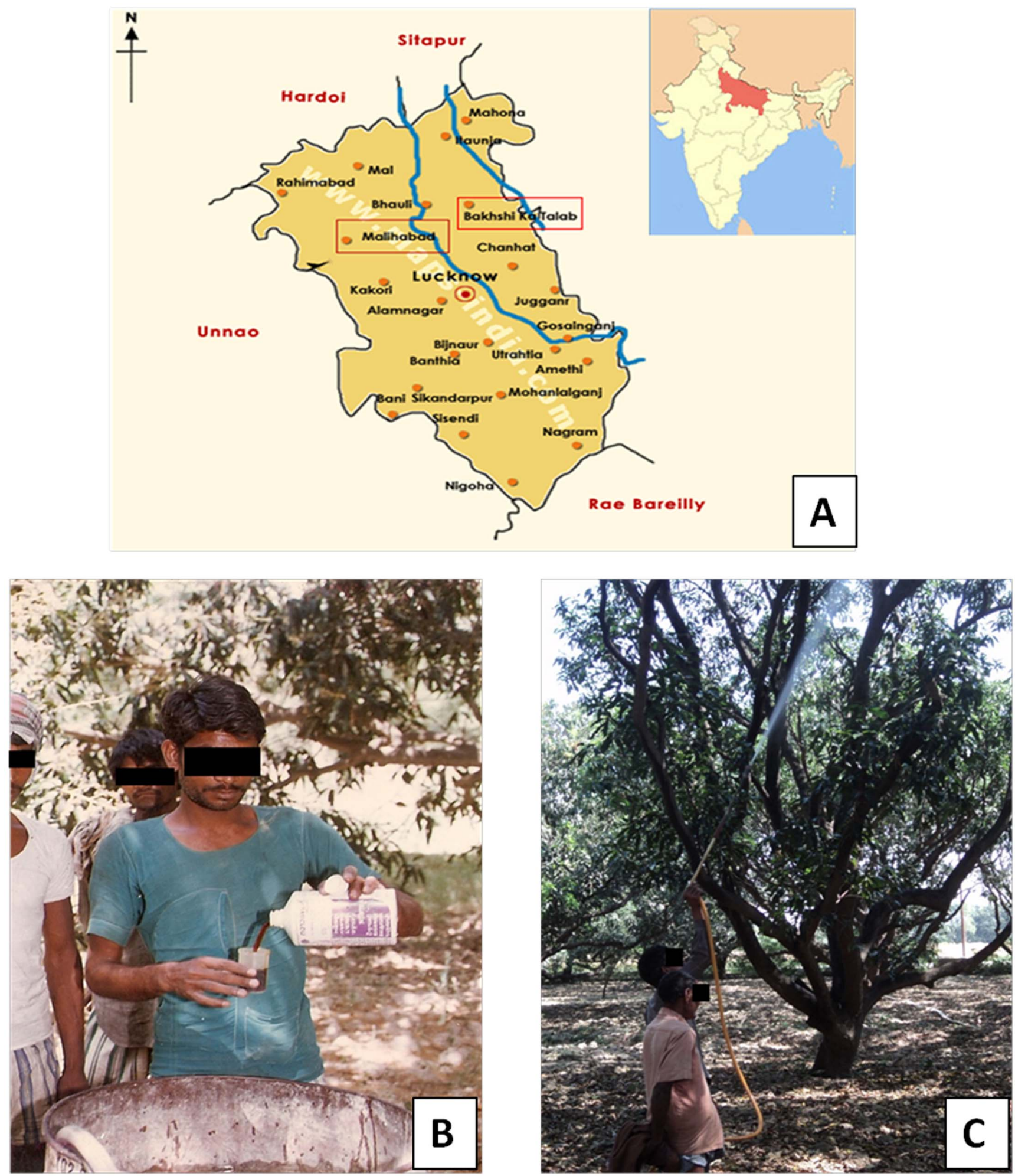

Figure 1. Study location and pesticide exposed subjects. (A) Map showing Malihabad and Bakshi Ka Talab regions of Lucknow district, figure in inset is map of India showing Uttar Pradesh state (dark filled); (B) Figure showing the handling of pesticide with bare hands by a sprayer; (C) Figure showing the spraying of pesticides without personal protective devices by sprayers. doi:10.1371/journal.pone.0069755.g001

to the lungs from the systemic circulation through inhalation and absorption, adversely affect the lung tissues [5]. The health effects of pesticide inhalation through occupational exposure have been documented in a number of epidemiologic studies reporting higher risk of respiratory symptoms [4,6,7]. Apart from respiratory symptomatology, a relatively small number of studies have 
attempted to assess the pulmonary function (by means of spirometry) after long-term pesticide exposure. Some earlier studies reported the higher prevalence of respiratory symptoms supported by reduced lung function test among agricultural workers occupationally exposed to pesticides [7-8].

Pesticides have been shown to have hematotoxic properties and may cause aplastic anemia, agranulocytosis, neutropenia, and thrombopenia [9]. Both acute and chronic exposure to toxic doses of pesticides may induce hematological, congenital abnormalities and thalassemia [10]. More interaction of organophosphate pesticides $(\mathrm{OP})$ with iron results in lesser binding efficiency of Hemoglobin with iron leading to anaemic conditions [11].

OP pesticides used by the agricultural workers inhibit the action of AChE, enzyme involved in the release of acetylcholine at the nerve endings [12], thus OP increases the cholinergic effects of acetylcholine in the body and depolarization of neural transmission [13]. Acetylcholinesterase (AChE) activity in the red blood cells and Butrylcholinesterase (BChE) activity in plasma have been used to monitor the extent of exposure of organophosphates (OP) which are considered as cholinesterase inhibiting pesticides [1213]. There is a correlation between exposure to OP pesticides and inhibition of AChE activity [14-15]. Therefore, the level of AChE activity has been considered a reliable biomarker for exposure to these pesticides [15-18].

The studies from Asian sub-continent including India is very important keeping in view of the incorrect work practices, nonusage of PPE etc. practised by pesticide sprayers during spraying operations in the field. Literature on the association of pesticide alterations among agrarian communities of Asian countries are scanty. In the present study we investigated the altered hematological profile along with symptoms of respiratory illness, lung function tests $\mathrm{FEV}_{1}$ (Forced Expiratory Volume in 1 second), PEFR (Peak Expiratory Flow Rate) and FVG (Forced Vital Capacity) for pulmonary impairment among agricultural workers in rural agricultural sector of Lucknow district in India. These subjects spray OP pesticides during agricultural work practices in unsafe environment without following any preventive and hygienic pesticides was also investigated to ascertain the exposure of OP pesticides among agricultural workers. The present study aims to explore the respiratory health and hematological profile among agricultural workers occupationally exposed to OP pesticides in North India. exposure with adverse respiratory health and hematological work practices. Cholinesterase levels as a biomarker of OP

\section{Materials and Methods}

\section{Study Design}

This is a cross sectional study for respiratory health related to agricultural pesticide exposure. The study was conducted at Malihabad and Bakshi Ka Talab regions of Lucknow district located in North India (Figure 1A). These areas have several mango plantations where agricultural workers spray pesticides to protect the mango crop from harmful pests and thereby enhancing the mango crop productivity. The pesticide sprayers have experience of spraying pesticides in mango plantation from 1-30 years. Spraying operations last for 2 to 8 hour/week per season on the trees of mango orchards from December to March every year. Mixing of chemicals with bare hands, leakages from tanks of pesticide during spraying operations were found to be very common. Sprayers of mango plantations were using OP pesticides like monocrotphos, dichlorvos, malathion, methyl parathion etc.

\section{Subjects}

We selected subjects on the basis of the results of a preliminary questionnaire specifically designed for this study. All the subjects were engaged in the spraying of OP pesticides without using any PPE. One hundred sixty six male pesticide sprayers participated in the study. The study was compared with 77 healthy males having no previous or current occupational exposure to pesticides taken as control from near by area with same socio-economic status. On the basis of area of living, ethnicity of both groups of subjects was almost similar. The purpose of the study was explained to all the participants and their consent was obtained. Subjects of the photograph shown in Figure $1(B)$ and $1(C)$ have given written informed consent, as outlined in the PLOS consent form, to publication of their photograph. All the health surveys, spirometry and collection of blood samples of pesticide sprayers were performed during the end phase of the pesticide application season in the month of March with time interval of 1-2 days after the last spraying operation.

Pesticide sprayers were randomly selected on the basis of inclusion and exclusion criteria.

Inclusion criteria of pesticide sprayers (exposed subjects) include:

1. Male pesticide sprayers with age group of 18-60 yrs.

2. Pesticide sprayers must have at least six months previous experience in spraying operations in the field.

Exclusion criteria of pesticide sprayers (exposed subjects) include:

Table 1. Physical characteristic, personal habits and exposure period of study subjects.

\begin{tabular}{|c|c|c|}
\hline Physical characteristics and personal habits & Controls $(\mathrm{N}=\mathbf{7 7})$ & Pesticide sprayers $(\mathrm{N}=166)$ \\
\hline Age (yrs) $[$ Mean $\pm S D]$ & $37.28 \pm 14.13$ & $38.12 \pm 15.39$ \\
\hline Weight $(\mathrm{Kg})[$ Mean $\pm \mathrm{SD}]$ & $52.76 \pm 13.54$ & $51.32 \pm 7.56$ \\
\hline Height $(\mathrm{cm})[$ Mean $\pm \mathrm{SD}]$ & $164.24 \pm 7.53$ & $163.94 \pm 6.16$ \\
\hline BMI $\left(\mathrm{Kg} / \mathrm{m}^{2}\right)$ & $20.03 \pm 4.34$ & $19.08 \pm 2.48$ \\
\hline Smokers [n (\%)] & $26(33.76)$ & $62(37.34)$ \\
\hline Tobacco chewers [n (\%)] & $23(29.87)$ & $41(24.69)$ \\
\hline Alcohol consumers [n (\%)] & $11(14.28)$ & $39(23.49)$ \\
\hline Pesticide exposure (yr.) & $0.0 \pm 0.0$ & $17.91 \pm 11.68^{* *}$ \\
\hline
\end{tabular}


Table 2. Information about the agricultural work practices followed by pesticide sprayers.

\begin{tabular}{|c|c|}
\hline Variables & Pesticide sprayers $(\mathrm{N}=166) \mathrm{n}(\%)$ \\
\hline \multicolumn{2}{|l|}{ Place for pesticide storage } \\
\hline Inside the house & $73(43.98)$ \\
\hline Inside plantation areas & $20(12.05)$ \\
\hline No storage & $30(18.07)$ \\
\hline Tools storage room & $50(30.12)$ \\
\hline \multicolumn{2}{|l|}{ Place for pesticide preparation and handling } \\
\hline In home & $30(18.07)$ \\
\hline In fields & $80(48.19)$ \\
\hline Near pond & $70(42.17)$ \\
\hline Handling of pesticide container by bare hands & $166(100)$ \\
\hline Mixing of pesticide by bare hands & $60(36.14)$ \\
\hline Mixing of pesticide by rod & $20(12.05)$ \\
\hline Mixing by motor & $100(60.24)$ \\
\hline \multicolumn{2}{|c|}{ Personal protecting equipment and awareness during mixing/loading/spraying } \\
\hline Use of gloves/goggles/apron & $0(0)$ \\
\hline Cloths wet during spraying & $120(72.29)$ \\
\hline Smoke while spraying & $45(27.11)$ \\
\hline Eat in the break between spraying & $75(45.18)$ \\
\hline Take bath after the end of spraying & $140(84.34)$ \\
\hline Change clothes at the end of work shift & 135 (81.32) \\
\hline Wash contaminated clothes with family clothes & $115(69.28)$ \\
\hline Any integrated pest management training taken & $0(0)$ \\
\hline \multicolumn{2}{|l|}{ Fate of empty packages/containers of pesticide } \\
\hline Buried/burned & $0(0)$ \\
\hline Discarded near the river/canal/field & $113(68.07)$ \\
\hline Use at home & $35(21.08)$ \\
\hline Sold to scrap dealer & $17(10.24)$ \\
\hline Used for some other work & $15(9.04)$ \\
\hline
\end{tabular}

doi:10.1371/journal.pone.0069755.t002

1. Pesticide sprayers less than $18 \mathrm{yrs}$ of age and greater than 2. Pesticide sprayers with less than six months work experience. $60 \mathrm{yrs}$.

3. Female subjects.

Table 3. Respiratory symptoms observed among study subjects.

\begin{tabular}{|c|c|c|c|c|c|c|c|c|}
\hline \multirow[t]{2}{*}{ Respiratory problems } & \multicolumn{3}{|c|}{ Controls ( $N=77$ ) n (\%) } & \multicolumn{3}{|c|}{ Pesticide sprayers $(N=166)$ n $(\%)$} & \multirow[t]{2}{*}{$\begin{array}{l}\text { Adjusted } \\
\text { odds ratio \# }\end{array}$} & \multirow[t]{2}{*}{$95 \% \mathrm{Cl}$} \\
\hline & Smokers & $\begin{array}{l}\text { Non } \\
\text { Smokers }\end{array}$ & Total & Smokers & $\begin{array}{l}\text { Non } \\
\text { Smokers }\end{array}$ & Total & & \\
\hline $\begin{array}{l}\text { Prevalence of overall } \\
\text { respiratory problems }\end{array}$ & $2(2.59)$ & $1(1.29)$ & $3(3.89)$ & $26(15.66)$ & $35(21.08)$ & $61(36.75)^{* *}$ & 14.33 & $4.37-73.52$ \\
\hline Dry cough & $1(1.29)$ & $0(0.0)$ & $1(1.29)$ & $8(4.81)$ & $12(7.22)$ & $20(12.05)^{* *}$ & 10.41 & $1.59-437.09$ \\
\hline Productive cough & $0(0.0)$ & $0(0.0)$ & $0(0.0)$ & $12(7.22)$ & $19(9.63)$ & $31(23.49)^{* *}$ & - & - \\
\hline Dyspnoea & $1(1.29)$ & $1(1.29)$ & $2(2.59)$ & $3(1.80)$ & $6(3.61)$ & $9(5.42)^{* *}$ & 2.15 & $0.43-20.87$ \\
\hline Wheezing & $0(0.0)$ & $0(0.0)$ & $0(0.0)$ & $4(2.40)$ & $5(3.01)$ & $9(5.42)^{* *}$ & - & - \\
\hline Irritation of throat & $0(0.0)$ & $0(0.0)$ & $0(0.0)$ & $1(0.60)$ & $2(1.20)$ & $3(1.81)^{* *}$ & - & - \\
\hline Blood stained sputum & $0(0.0)$ & $0(0.0)$ & $0(0.0)$ & $2(1.20)$ & $1(0.60)$ & $3(1.81)^{* *}$ & - & - \\
\hline
\end{tabular}


Table 4. Lung function tests among study subjects.

\begin{tabular}{|c|c|c|}
\hline Lung function parameters & Controls $\mathrm{N}=\mathbf{7 7}$ ) & Pesticide sprayers $(N=166)$ \\
\hline PEFR (Lt/min) $[$ Mean \pm SD] & $440.44 \pm 112.45$ & $306.34 \pm 108.46^{* *}$ \\
\hline $\mathrm{FEV}_{1}(\mathrm{Lt})[$ Mean $\pm \mathrm{SD}]$ & $2.26 \pm 0.59$ & $1.76 \pm 0.63^{* *}$ \\
\hline$\%$ PEFR predicted $[$ Mean \pm SD] & $81.09 \pm 20.34$ & $60.03 \pm 20.74^{* *}$ \\
\hline$\%$ FEV1 predicted [Mean \pm SD] & $77.95 \pm 18.17$ & $64.41 \pm 24.73^{* *}$ \\
\hline FVC (Lt) [Mean \pm SD] & $2.23 \pm 0.74$ & $2.20 \pm 0.77$ \\
\hline FEV1/FVC [Mean \pm SD] & $0.84 \pm 0.01$ & $0.79 \pm 0.01^{* *}$ \\
\hline
\end{tabular}

Control subjects were randomly selected on the basis of inclusion and exclusion criteria.

Inclusion criteria of control subjects include:

Male resident who did not handle pesticides and having similar socio economic status and age group of exposed subjects.

Exclusion criteria of control subjects include:

1. Male subjects with age group less than 18 yrs of age and greater than 60 yrs and those handling pesticides.

\section{Female subjects}

The criteria for the withdrawal of subjects: If sprayer or control subject did not wish to participate in the study after giving detail explanation of the study, he was free to discontinue/withdraw at any stage of procedure viz., collection of personal background information or during clinical procedures.

\section{Questionnaire}

A preliminary questionnaire was designed to record the personal and occupational information along with pesticide exposure and respiratory health status of the pesticide sprayers. Each pesticide sprayer was interviewed based on questionnaire like general information about the name, age, smoking habit of individual pesticide sprayer; information about the exposure period of pesticide spraying in respect of years; information about the use of pesticide like the type of pesticide they spray, methods of spraying the pesticides, information about the work practices followed by them during spraying the pesticides such as whether they handle the pesticides with bare hands or measuring cup, whether they wear any protective equipment, whether they eat anything while spraying, whether they take bath after spraying etc.; respiratory health information through clinical examination.

\section{Clinical Examination}

Clinical examination for respiratory health was done by a medical expert and the symptoms for respiratory illness were recorded in the questionnaire for every individual who participated in this study. Human ethical clearance was obtained from "Human Ethics Committee" of Indian Institute of Toxicology Research for collecting the blood samples and clinical investigations of the participants. No minors/children participants were involved in this study. All the participants were above the age of 18 years. All the participants provided their written informed consent to participate in this study which was approved by Institutional Human Ethics Committee. All the documents including questionnaires and consent forms of all the participants were safely kept for data analysis.

\section{Blood Sample Collection}

Approximately $3.0 \mathrm{ml}$ venous blood was collected in the heparinised glass vials as coded samples from both the control and sprayers. Samples were transported to the laboratory of Epidemiology division of Indian Institute of Toxicology Research, Lucknow, India in ice-cold condition immediately after the collection. The hematological investigation and cholinesterase measurement were carried out on same day of blood collection.

\section{Chemicals and Reagents}

5,5'-dithio-bis-(2-nitrobenzoic acid) (DTNB), sodium dodecyl sulphate (SDS), tris $\mathrm{HCl}$ buffer, acetylthiocholine iodide and butrylthiocholine iodide, were from Sigma Chemical Co., St. Louis, MO. All the other chemicals used were of the highest purity available from commercial sources.

\section{Cholinesterase Measurement}

Blood AChE and BChE activities were assayed by the method Ellman et al, 1961 [19] as modified by Chambers and Chambers,

Table 5. Exposure wise distribution of respiratory illness among pesticide sprayers.

\begin{tabular}{llll}
\hline $\begin{array}{l}\text { Spraying duration } \\
\text { (no. of years } \times \text { no. of hours) }\end{array}$ & No. of subjects (\%) & $\begin{array}{l}\text { No. of cases having } \\
\text { respiratory illness (\%) }\end{array}$ & Odds ratio* \\
\hline$<11$ & $60(36.14)$ & $16(26.67)$ & 1.00 \\
$11-50$ & $54(32.53)$ & $20(37.03)$ & 1.62 \\
$51-100$ & $32(19.28)$ & $15(46.87)$ & 2.43 \\
101 and above & $20(12.05)$ & $10(50.00)$ & 2.75 \\
\hline
\end{tabular}

${ }^{*}$ Chi square for linear trend is 5.087 ( $p$-value $=0.02$ ).

doi:10.1371/journal.pone.0069755.t005 
Table 6. Cholinesterase activity (IU/L) among study subjects.

\begin{tabular}{lll}
\hline & & \\
\hline Cholinesterase activity (IU/L) & Control $(\mathbf{n}=\mathbf{7 7})$ & Pesticide sprayers $(\mathbf{n}=\mathbf{1 6 6})$ \\
\hline Acetylcholinesterase $[$ Mean \pm SD] & $570.24 \pm 306.71$ & $420.28 \pm 239.62^{* *}$ \\
Butyrylcholinesterase $[$ Mean \pm SD] & $434.91 \pm 218.46$ & $253.76 \pm 186.30^{* *}$ \\
\hline$* * p<0.01$. & & \\
doi:10.1371/journal.pone.0069755.t006 & &
\end{tabular}

1989 [20] by taking acetylthiocholine iodide and butyrylthiocholine iodide respectively as substrate and expressed as mmols hydrolyzed/h/l blood (IU/L). The AChE and BChE were measured as a biomarker of OP pesticides exposure among study subjects.

\section{Hematology}

Standard protocol for hematological investigation was undertaken on each sprayer and controls. Hematological indices studied were total red blood count, total leukocyte count, differential leukocyte count, hemoglobin percentage, hematocrit, mean corpuscular volume (MCV), mean corpuscules hemoglobin concentration $(\mathrm{MCH})$ and platelet count. Hematology analyzer (Arcus, Diatron) was used for complete blood count. The procedure followed was as per the instruction manual of Hematology Analyser (Arcus, Diatron). $25 \mu \mathrm{l}$ of anti-coagulated whole blood sample was aspirated by the sampling needle (present in sampling bar), and $4 \mathrm{ml}$ of diluent was added into the chamber. $25 \mu \mathrm{l}$ of primary dilution was aspirated and stored in the needle during the WBC measurement. $0.9 \mathrm{ml}$ of lysing reagent was added to the primary dilution remaining in the chamber. After the WBC measurement and a washing process, the instrument made the second dilution into the chamber with the sample stored in the needle and with $5 \mathrm{ml}$ of diluent reagent, then the other hematological parameters were detected. The lysing agent and diluent were provided with the instrument. Both the lower limit and upper limit from the normal range for each hematological parameter was taken as cases with variation.

\section{Lung Function Test}

Lung function tests $\mathrm{FEV}_{1}$ (Forced Expiratory Volume in 1 second), PEFR (Peak Expiratory Flow Rate) and FVC (Forced Vital Capacity) for pulmonary impairment of each subject (pesticide sprayers and control) were performed using a Spirometer (PIKO-1, UK under the recommendation of the American Thoracic Society standards). The purpose of the lung function test was to evaluate pulmonary impairments among study subjects. The volunteer performed the lung function test three times allowing for sufficient rest between repetitions. The best values for PEFR, $\mathrm{FEV}_{1}$ and FVG from three tests for each subject were recorded. Results were interpreted with the predicted values of lung function parameters calculated by reference equation for Indian population [21].

\section{Statistical Analysis}

Descriptive statistics have been generated for the demographic parameters in the control group and pesticide sprayers. Frequencies and percentages have been shown for all the categorical parameters. Student's t test has been used to compare the mean values of the quantitative characteristics (demographic parameters, spirometry parameters and cholinesterase activity) between the control and exposed group. Chi square test has been incorporated for comparison of the categorical outcomes (hematological abnormalities, pulmonary impairments, respiratory problems). Fisher's exact test has been used in cases where the expected cell frequencies were less than 5. Chi-square test for linear trend was used for exposure wise distribution of respiratory illness among pesticide sprayers. The calculation of odds ratio with $95 \%$ confidence interval (CI) for respiratory and hematological alterations in respect to potential risk factors has been performed using logistic regression models. Odds ratio for respiratory symptoms were adjusted for smoking using multivariate logistic regression analysis. Linear regression analysis was done considering PEFR and spray duration as independent variables and $\mathrm{FEV}_{1}$ and PEFR as the dependent variables respectively. The criterion for significance was set at $p<0.05$. All the statistical analysis has been performed using EPI INFO 7.1.1.0 software (Centre for Disease Control and Prevention, Georgia, USA) and IBM SPSS Statistics version 20

\section{Results}

\section{Physical Characteristics, Personal Habits and Exposure Period of Study Subjects}

Table 1 exhibits the physical characteristics, personal habits and exposure period of study subjects. Age, height, weight and BMI were found to be almost similar among controls and pesticide sprayers. Smokers and alcohol consumers were found to be insignificantly more in pesticide sprayers group than controls; whereas tobacco chewers were found to be insignificantly more in controls group than pesticide sprayers group. Mean pesticide exposure among sprayers was found to be $17.91 \pm 11.68$ years.

\section{Information about the Agricultural Work Practices followed by Pesticide Sprayers}

Table 2 shows the information about different agricultural work practices followed by pesticide sprayers which are based on preliminary questionnaire designed for this study. Information about the place of pesticide storage, place for pesticide preparation and handling, personal protecting equipment and awareness during mixing/loading/spraying, fate of empty packages/containers of pesticide are shown in this table.

\section{Self Reported Respiratory Problems among Study Subjects}

Table 3 shows various respiratory problems viz. dry cough, productive cough, dyspnoea, wheezing, irritation of throat, blood stained sputum, observed among pesticide sprayers and control subjects stratified by smoking habits. Prevalence of overall respiratory problems among study subjects which was found to be $36.75 \%$ (AOR- 14.33 ; 95\% CI- 4.37-73.52) which was highly significant $(\mathrm{p}<0.01)$ as compared to controls $(3.89 \%)$; respiratory problems like dry cough (AOR- 10.41; 95\% CI- 1.59-437.09), Dyspnoea (AOR- 2.15; 95\% CI- 0.43-20.87) were found to be significantly more among pesticide sprayers as compared to controls. No cases among control group were observed for 


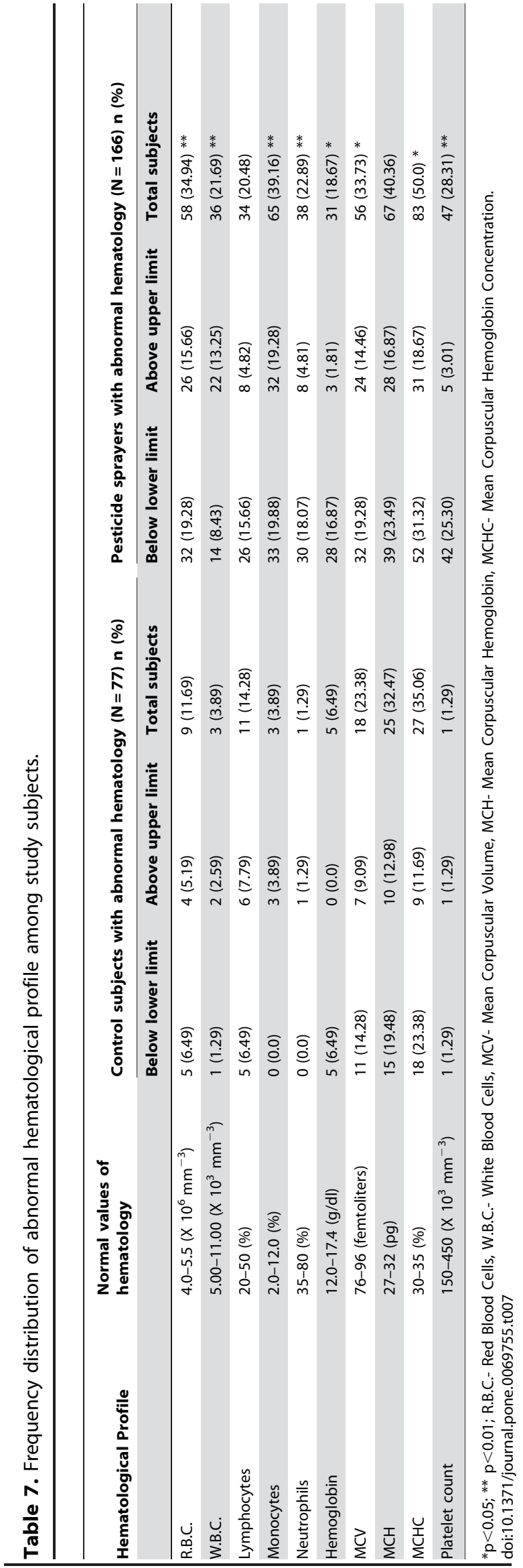

productive cough, wheezing, irritation of throat and blood stained sputum.

\section{Lung Function Tests among Study Subjects}

Table 4 exhibits lung function parameters viz. PEFR, FEV , $_{1}$ $\%$ PEFR predicted, $\% \mathrm{FEV}_{1}$ predicted, $\mathrm{FVC}, \mathrm{FEV}_{1} / \mathrm{FVG}$ of controls and pesticide sprayers group in which all the parameters for lung functions except FVC were found to be significantly decreased $(\mathrm{p}<0.01)$ among pesticide sprayers as compared to controls.

\section{Exposure Wise Distribution of Respiratory Illness}

Table 5 shows exposure wise distribution of respiratory illness among pesticide sprayers which illustrates that exposure time elevates the respiratory problems among pesticide sprayers. Pesticide exposure was taken into consideration as product of number of years and number of hours (no. of years $\times$ no. of hours); number of hours are the average hours of spraying pesticides per week throughout the year, and according to which 4 groups were established, namely $<11,11-50,51-100,101$ and above. It was seen that the group having most time of pesticide exposure exhibited most prevalence of respiratory problems. Odd ratio also shows regular increment pattern as exposure time increases, chisquare value for linear trial was found to be 5.09 and p-value was found to be 0.02 which shows statistical significance for increasing trend in prevalence of respiratory illness observed with increasing pesticide exposure.

\section{Activities of Cholinesterase Enzymes}

The biomarkers of organophosphate pesticides exposure viz., AChE and BChE activity in blood among pesticide sprayers was analysed and the results shown in Table 6. Activities of both AChE and BChE among pesticide sprayers were found to be significantly depleted $(\mathrm{p}<0.01)$ as compared to control subjects.

\section{Hematological Findings}

Frequency distribution of hematological variations among study subjects are shown in Table 7. Significant $(\mathrm{p}<0.05)$ abnormal counts considering both below lower limit and above upper limit from normal range were found for R.B.C., W.B.C., Neutrophils, Hemoglobin, MCV, MCHC and platelets among pesticides sprayers as compared to control subjects. Table 8 shows the association of respiratory problems with hematology among study subjects showing significantly $(\mathrm{p}<0.01)$ increasing hematological alterations (OR- 3.94; 95\% CI- 2.02-7.67) among subjects with respiratory problems as compared to those subjects without respiratory problems.

\section{Correlations of Lung Function Parameters with Cholinesterase and Spray Duration}

Correlations of all the lung function parameters viz. PEFR, $\mathrm{FEV}_{1}, \%$ PEFR predicted, $\% \mathrm{FEV}_{1}$ predicted, FVC, $\mathrm{FEV}_{1} / \mathrm{FVC}$ with AChE, BChE and spray duration among pesticide sprayers are shown in Table 9. PEFR is significantly correlated $(\mathrm{p}<0.01)$ with spray duration; $\mathrm{FEV}_{1}$ is significantly correlated $(\mathrm{p}<0.01)$ with AChE and spray duration; \%PEFR predicted is significantly correlated $(\mathrm{p}<0.01)$ with spray duration; predicted $\% \mathrm{FEV}_{1}$ predicted is significantly correlated $(\mathrm{p}<0.01)$ with $\mathrm{AChE}$; FVC is significantly correlated $(\mathrm{p}<0.01)$ with $\mathrm{AChE}$ and spray duration; $\mathrm{FEV}_{1} / \mathrm{FVC}$ is significantly correlated $(\mathrm{p}<0.01)$ with $\mathrm{AChE}$ and spray duration. 
Table 8. Association of respiratory problems with hematology among pesticide sprayers.

\begin{tabular}{|c|c|c|c|c|}
\hline \multirow[t]{2}{*}{ Subjects } & \multicolumn{2}{|c|}{ With respiratory symptoms } & \multicolumn{2}{|c|}{ Without respiratory symptoms } \\
\hline & $\begin{array}{l}\text { Having normal } \\
\text { haematology }\end{array}$ & $\begin{array}{l}\text { Having altered } \\
\text { haematology* }\end{array}$ & $\begin{array}{l}\text { Having normal } \\
\text { haematology }\end{array}$ & $\begin{array}{l}\text { Having altered } \\
\text { haematology* }\end{array}$ \\
\hline Pesticide sprayers $(n=166) n(\%)$ & $23(13.85)$ & $38(22.90)$ & $74(44.60)$ & $31(18.68)$ \\
\hline Controls $(\mathrm{N}=77) \mathrm{n}(\%)$ & $1(1.2)$ & $2(2.59)$ & $58(75.32)$ & 16(20.77) \\
\hline
\end{tabular}

*Altered haematology is considered if one or more than one parameters are out of normal range.

Odds Ratio = $3.94(95 \% \mathrm{Cl}=2.02-7.67) ; \mathrm{p}<0.01$.

doi:10.1371/journal.pone.0069755.t008

\section{Discussion}

Pesticide sprayers in the present study were unaware of the health risks associated with spraying, as most of them were illiterate and did not used any precautionary measures while spraying of pesticides. These pesticide sprayers never used PPE during spraying operations. Mixing of chemicals with bare hands and pesticide leakage from tanks during spraying operations was found to be very common. Due to upward spraying in the mango orchards even with mechanized spraying equipment, pesticides fell

Table 9. Linear regression analysis of Lung function parameters with $\mathrm{AChE}, \mathrm{BChE}$ and spray duration among pesticide sprayers.

\begin{tabular}{|c|c|c|c|c|}
\hline $\begin{array}{l}\text { Risk } \\
\text { factors }\end{array}$ & $\begin{array}{l}\text { Statistical } \\
\text { coefficients }\end{array}$ & AChE & BChE & $\begin{array}{l}\text { Spray } \\
\text { duration }\end{array}$ \\
\hline \multirow[t]{4}{*}{ PEFR } & r value & -0.17 & 0.06 & -0.41 \\
\hline & $\beta$ coefficient & -0.11 & 0.01 & -0.41 \\
\hline & $\mathrm{F}$ value & -1.19 & 0.16 & -4.75 \\
\hline & $p$ value & 0.24 & 0.88 & $<0.01$ \\
\hline \multirow[t]{4}{*}{$\mathrm{FEV}_{1}$} & $r$ value & -0.26 & 0.05 & -0.37 \\
\hline & $\beta$ coefficient & -0.24 & 0.07 & -0.30 \\
\hline & F value & -2.60 & 0.78 & -3.48 \\
\hline & $p$ value & $<0.05$ & 0.43 & $<0.01$ \\
\hline \multirow{4}{*}{$\begin{array}{l}\text { \%PEFR } \\
\text { predicted }\end{array}$} & $r$ value & -0.15 & 0.03 & -0.27 \\
\hline & $\beta$ coefficient & -0.11 & 0.02 & -0.26 \\
\hline & F value & 0.17 & -1.15 & -2.86 \\
\hline & $p$ value & 0.87 & 0.25 & $<0.01$ \\
\hline \multirow{4}{*}{$\begin{array}{l}\% \mathrm{FEV}_{1} \\
\text { predicted }\end{array}$} & $r$ value & -0.19 & -0.06 & 0.01 \\
\hline & $\beta$ coefficient & -0.22 & 0.04 & 0.07 \\
\hline & F value & 0.39 & -2.21 & 0.73 \\
\hline & $p$ value & 0.69 & $<0.05$ & 0.47 \\
\hline \multirow[t]{4}{*}{ FVC } & $r$ value & -0.26 & 0.04 & -0.35 \\
\hline & $\beta$ coefficient & -0.24 & 0.07 & -0.29 \\
\hline & $\mathrm{F}$ value & -2.58 & 0.76 & -3.32 \\
\hline & $p$ value & 0.45 & $<0.05$ & $<0.01$ \\
\hline \multirow[t]{4}{*}{$\mathrm{FEV}_{1} / \mathrm{FVC}$} & r value & -0.20 & 0.12 & -0.59 \\
\hline & $\beta$ coefficient & -0.13 & 0.06 & -0.56 \\
\hline & $\mathrm{F}$ value & -1.58 & 0.71 & -7.41 \\
\hline & $p$ value & 0.48 & 0.115 & $<0.01$ \\
\hline
\end{tabular}

onto the body of the sprayers. During spraying, these workers wore minimum clothes, i.e. only underwear and not even vests because of the tropical climate in North India.

Inhalation of pesticides on the worksite occurs, provided that one or more of the following conditions exist: the chemical in use is quite volatile; application is in an enclosed poorly ventilated area, or the manner of application leads to an aerosol cloud of finely dispersed droplets that do not readily settle [22]. Small aerosol droplets of pesticides during spraying remain suspended in the air and may be inhaled by pesticide sprayers. Once inhaled, pesticide aerosols or vapors may react with airways, producing irritant effects and further airway narrowing. Moreover, if the droplet size is small enough it can reach the alveolar space and damage the alveolar capillary membrane, leading to gas diffusion impairment [23].

In the present study, respiratory symptoms like dry cough, productive cough, wheezing, irritation of throat and blood stained sputum were found to be significantly more among pesticide sprayers. Parameters of lung function tests viz. PEFR, FEV , $\%$ PEFR predicted, $\% \mathrm{FEV}_{1}$ predicted, $\mathrm{FEV}_{1} / \mathrm{FVC}$ were found to be significantly less among pesticide sprayers which show the pulmonary impairments among them. Lung function impairments were found to be more among pesticide sprayers in comparison to control subjects, which is in agreement with an earlier study [24] reporting that pesticides can cause laryngeal and bronchial constriction. We have correlated the exposure duration of pesticides in years and hours with the prevalence of respiratory symptoms and found a regular increment pattern in prevalence of respiratory symptoms which illustrates that exposure duration causes more respiratory illness due to pesticides. Likewise exposure wise distribution of PEFR, $\mathrm{FEV}_{1}$ \% $\mathrm{PEFR}$ predicted, $\mathrm{FEV}_{1} / \mathrm{FVC}$ among pesticide sprayers shows that exposure duration of pesticides increases the lung function alterations. Recently our group has reported significant depletion in blood AChE activity and $\mathrm{FEV}_{1}$ among pesticide sprayers in post spraying season as compared to pre spraying season [25]. Several epidemiological and toxicological studies have shown results comparable to those of present study. A cross sectional study was conducted in Canada on 1939 farmers for pesticides and their respiratory effects: pesticide use was associated with isolated asthma and pulmonary function change [26]. Some earlier studies depicted that pesticides associated with respiratory symptoms included organophosphates, thiocarbamates, paraquat, [27] and carbamates [26]. In the Iowa farm family health and hazard surveillance project, among farmers, a study among agricultural workers in Iowa found a clear association of pesticide use with respiratory symptoms [28]; in Ohio, rural work involving pesticides was related to the significantly increased chronic cough [3]. The observation of a decreased $\mathrm{FEV}_{1}$ with depleted cholinesterase levels among pesticide sprayers in present study shows agreement with some 
earlier studies in which they showed short-term exposure to anticholinesterase insecticides (OP pesticides) lead to transient obstructive lung dysfunction owing to large airway narrowing $[23,29,30]$.

Anticholinesterase pesticides i.e organophosphates used by the pesticide sprayers in the present study were neurotoxic in nature, so the AChE and BChE activities were found to be significantly depleted among the pesticide sprayers than that of control group. The decreased activity of AChE and BChE in the exposed subjects can be related to OP pesticide exposure in the present study considering them as good indicators for OP toxicity. Cholinesterase depletion is well correlated with use of organophosphate pesticides during the farming season [8,31]. In some earlier studies, AChE inhibition was found to be significantly associated with OP pesticide toxicity [32-33]. AChE inhibition was observed among desert farm workers exposed to OP and carbamates [34]. The depletion of AChE reported in the UAE workers occupationally exposed to OP pesticides correlated well with the frequency of usage and length of use [8,35-36]. Decreased activity of BChE due to OP exposure in the present study supports the earlier report [37]. In a similar study [38], inhibition of BChE due to $\mathrm{OP}$ exposure was reported but results were non-significant. As in our study, similar observations were found in some earlier studies where pesticide sprayers having respiratory illness and altered lung functions showed depleted cholinesterase activities [23,29].

The alterations observed in the hematological parameters of sprayers can be related to OP pesticides exposure which is evidenced by decreased AChE and BChE activity. RBC, WBC, monocytes, neutrophils, MCV, MCH, MCHC and platelet count of sprayers show significant alterations compared to controls which can be related to OP pesticide exposure. Similar observation on abnormal haematogical profile viz. haematocrit, RBC, WBC and platelet count was previously reported among pesticide exposed farm workers [39-40]. Excess risks of Chronic Lymphoid Leukemia and Multiple Myleloma have been found in various studies among farmers [41-43], and pesticide exposure has been suggested as the cause. Variations in WBC, hemoglobin, hematocrit and platelets count was also reported in pesticide exposed population in a study with small sample size [37]. Hematological abnormalities including instances of leukopenia, leucocytosis, lymphocytopenia, lymphocytosis, neutropenia,

\section{References}

1. Kimbell-Dunn MR, Fishwick RD, Bradshaw L, Erkinjuntti-Pekkanen R, Pearce $\mathrm{N}$ (2001) Work-related respiratory symptoms in New Zealand farmers. Am J Ind Med 39(3): 292-300.

2. Radon K, Danuser B, Iversen M, Jorres R, Monso E, et al. (2001) Respiratory symptoms in European animal farmers. Eur Respir J 17(4): 747-754.

3. Wilkins JR 3rd, Engelhardt HL, Rublaitus SM, Crawford JM, Fisher JL, et al. (1999) Prevalence of chronic respiratory symptoms among Ohio cash grain farmers. Am J Ind Med 35(2): 150-63.

4. Hoppin JA, Umbach DA, London SJ, Lynch CF, Alavanja MCR, et al. (2006) Pesticides and Adult Respiratory Outcomes in the Agricultural Health Study. Annals New York Academy of Sciences 1076: 343-354.

5. Dinsdale D, Ballantyne B, Mans TC (1992) Pulmonary toxicity of anticholinesterases. Clinical and experimental toxicology of organophosphates and carbamates, London: Butterworth Heinemann 156-166.

6. Zhang LX, Enarson DA, He GX, Li B, Chan-Yeung M (2002) Occupational and environmental risk factors for respiratory symptoms in rural Beijing, China. Eur Respir J 20: 1525-1531.

7. Bener A (1999) Respiratory symptoms, skin disorders and serum IgE levels in agricultural workers. Allerg Immunol Paris 31: 52-56.

8. Kossmann S, Konieczny B, Hoffmann A (1997) The role of respiratory muscles in the impairment of the respiratory system function in the workers of a chemical plant division producing pesticides. Przegl Lek 54: 702-706.

9. Parent D, Thouvenot D (1993) In vitro study of pesticide hematotoxicity in human and rat progenitor. J Pharmacol Toxicol Methods 30(4): 203-207. monocytosis, anaemia and thrombocytopenia were reported in the exposed subjects in the present study. Leukocytosis with abnormal count of lymphocytes and monocytes due to pesticide exposure have been reported in earlier human studies [44-45]. The decrease in RBC count and hemoglobin content may be due to disruptive action of the pesticides on the erythropoietic tissue as a result of which the viability of the cells might be affected [46]. In an earlier report [47], aplastic anaemia was found among farm workers exposed to agricultural pesticides. Hematological alterations observed in this study could be due to exposure of $\mathrm{OP}$ pesticides or due to respiratory problems observed among the pesticide sprayers.

\section{Conclusion}

It is concluded from this study that agricultural workers who are occupationally exposed to OP pesticides, showed adverse respiratory health and hematological alterations. The exposure of OP pesticides among them caused various respiratory problems, altered lung functions and hematological abnormalities. Due to unawareness of the hazardous health effects of pesticides among agricultural workers, they followed incorrect work practices without taking any safe and precautionary measures of handling and spraying pesticides, which eventually resulted in exposure of pesticides among them. It is very necessary to monitor health risks associated with pesticide exposure regularly among agricultural workers and make awareness programme with implementation of proper legislations for safe methods of spraying pesticides, so that the adverse health effects among agricultural workers could be minimised.

\section{Acknowledgments}

The authors acknowledge Dr. K. G. Gupta, Director, CSIR- Indian Institute of Toxicology Research, Lucknow for his encouragement and providing all necessary facilities required for this study.

\section{Author Contributions}

Conceived and designed the experiments: MF CNK MKP AKS. Performed the experiments: MF GNK MKP. Analyzed the data: MF CNK MKP VB RK AKS. Contributed reagents/materials/analysis tools: CNK AKS. Wrote the paper: MF GNK AKS.

10. Khristeva V, Mirchev N (1993) Changes in the blood system under chronic toxic pressure. Probl Khig 18: 97-105.

11. Worthing CR (1987) The Pesticide Manual: A World Compendium, $8^{\text {th }}$ ed. The British Crop Protection Council.

12. Rama DBK (1995) Cholinesterase enzyme reaction and inhibition by pesticides. African News. Occup Health Safety 5: 17-19.

13. Roldan-Tapia L, Nieto FA, Aguilla EM, Laynez F, Parron T, et al. (2006) Neurophysiologial sequela from acute poisoning and long term exposure to carbamate and organophosphate pesticides. Neurotoxicology and Teratology 28: 694-703.

14. Pathak MK, Fareed M, Bihari V, Reddy MMK, Patel DK, et al. (2011) Cholinesterase levels and morbidity in pesticide sprayers in North India. Occupational Medicine 61(7): 512-514.

15. Rama DB, Jaga K (1992) Pesticide exposure and cholinesterase levels among farm workers in the Republic of South Africa. Sci. Total Environ 122: 315-319.

16. Eason C, O'Halloran K (2002) Biomarkers in toxicology versus ecological risk assessment. Toxicology 64: 1739-44.

17. Joshaghani HR, Ahmadi AR, Mansourian MR (2007) Effects of occupational exposure in pesticide plant on workers serum and erythrocyte cholinesterase activity. International Journal of Occupational Medicine and Environmental Health 20: 381-85.

18. Remor AP, Totti CC, Moteira DA, Dutra GP, Heuser VD, et al. (2009) Occupational exposure of farm workers to pesticides: Biochemical parameters and evaluation of genotoxicity. Environment International 35: 273-8. 
19. Ellman GL, Curtney KD, Andrews V, Featherstone RM (1961) A new and rapid colorimetric determination of acetyl cholinesterase activity. Biochem Pharmacol 7: 88-95.

20. Chambers JE, Chambers HW (1989) An investigation of acetylcholinesterase inhibition and aging and choline acetyltransferase activity following a high level acute exposure to paraoxon. Pest Biochem Physiol 33: 125-131.

21. Rastogi SK, Mathur N, Clark SH (1983) Ventilatory norms in healthy industrial male workers. Ind J Chest Dis Allied Sci 25: 186-95.

22. American Thoracic Society (1998). Respiratory health hazards in agriculture. Am J Respir Crit Care Med 158: S1-S76.

23. Hernandez AF, Ignacio C, Gloria P, Fernando G, Enrique V, et al. (2008) Low Level of Exposure to Pesticides Leads to Lung Dysfunction in Occupationally Exposed Subjects. Inhalation Toxicology 20(9): 839-849.

24. Pathak MK, Fareed M, Srivastava AK, Pangtey BS, Bihari V, et al. (2013) Seasonal variations in cholinesterase activity, nerve conduction velocity and lung function among sprayers exposed to mixture of pesticides. Environ Sci Pollut Res (DOI 10.1007/s11356-013-1743-5).

25. Do PG (1992) Hazardous exposure and lung disease among agricultural workers. Occupational Lung Diseases 13: 311-328.

26. Senthilselvan A, McDuffie HH, Dosman JA (1992) Association of asthma with use of pesticides- results of a cross-sectional survey of farmers. Am Rev Respir Dis 146: 884-887.

27. Hoppin JA, Yucel F, Dosemeci M (2002) Accuracy of self reported pesticide use duration information from licensed pesticide applicators in the Agricultural Health Study. J Expo Anal Environ Epidemiol 12: 313-18.

28. Sprince NL, Lewis MQ Whitten PS, Reynolds SJ, Zwerling C (2000) Respiratory symptoms: associations with pesticides, silos, and animal confinement in the Iowa Farm Family Health and Hazard Surveillance Project. Am J Ind Med 38: 455-462.

29. Kesavachandran CN, Singh VK, Mathur N, Rastogi SK, Siddiqui MKJ, et al. (2006) Possible mechanism of pesticide toxicity-related oxidative stress leading to airway narrowing. Red Rep 11(4): 1-4.

30. Spiegiel RW, Gouriey DR, Holeslaw TL (1981) Organophosphate pesticide exposure in farmers and commercial applicators. Clinical Toxicology Consultant 3: $45-50$.

31. Lopez-Carillo L, Lopez-Cervantes M (1993) Effects of exposure to organophosphates on serum cholinesterase levels. Archives of Environment Health 48: 35963.

32. He F (1999) Biological monitoring of exposure to pesticides: current issues. Toxicol Lett 108(2-3): 277-283.
33. McConnell R, Magnotti R (1994) Screening for insecticide overexposure under field conditions- a re-evaluation of the tintimetric cholinesterase kit. Am J Public Health 84: 479-481.

34. Gomes J, Lloyd O, Revitt DMF, Norman JN (1997) Erythrocyte cholinesterase activity levels in desert farm workers. Occup Med 47(2): 90-94.

35. Yamanaka S, Yoshida M, Yamamura Y, Nishimura M, Takaesu Y (1993) A study of acute organophosphorous poisoning- changes in the activity and isoenzyme patterns of serum cholinesterase in human poisoning. Nippon Eiseigaku Zasshi- Jap J Hyg 48: 955-965.

36. Robinson DG, Trites DG, Banister EN (1993) Physiological effects of work. Ergonomics 36: 951-961.

37. Rastogi SK, Singh VK, Kesavachandran C, Jyoti, Siddiqui MKJ, et al. (2008) Monitoring of plasma butyrylcholinesterase activity and haematological parameters in pesticide sprayers. Indian Journal of Occupational and Environmental Medicine 12: 29-32.

38. Mekonnen Y, Ejigu D (2005) Plasma cholinesterase level of Ethiopian farm workers exposed to chemical pesticide. Occup Med 55: 504-505.

39. Del PL, Leilanie J (2007) Pesticide exposure, risk factors and health problems among cutflower farmers: a cross sectional study. J Occ Med Tox: 2-9.

40. Fareed M, Pathak MK, Bihari V, Reddy MMK, Patel DK, et al. (2010) Hematological and biochemical alterations in sprayers occupationally exposed to mixture of pesticides at a mango plantation in Lucknow, India. Toxicological \& Environmental Chemistry 92(10): 1919-1928.

41. Demeres PA, Vaughan TL, Koepsell TD (1993) A case_control study of multiple myeloma and occupation. Am J Ind Med 23: 629-639.

42. Blair A, Zahm SH, Pearce NE, Heineman EF, Fraumeni JF (1992) Clues to cancer etiology from studies of farmers. Scand J Work Environ Health 18: 209 215.

43. Swaen GM, Vliet C, Slangen JJ, Sturmans F (1992) Cancer mortality among licensed herbicide applicators. Scand J Work Environ Health 18: 201-204.

44. Wesseling C, McConnell R, Partanen T (1997) Agricultural pesticide use in developing countries: Health effects and research needs. Int J Health Serv 27: 273-308.

45. Brown L, Blair A, Gibson R (1990) Pesticides exposure and other agricultural risk factors for leukemia among men in lowa and Minnesota. Cancer Res 50: 6585-6591.

46. Sungur M, Guven M (2001) Intensive care management of organophosphate insecticide poisoning. Crot Care 5: 211-215.

47. Issaragrisil S, Chansung K, Kaufman DW, Sirijirachai J, Thamprasit T, et al. (1997) Aplastic anemia in rural Thailand: its association with grain farming and agricultural pesticide exposure. Am J Pub Health 87 (9): 1551-1554. 